be allowed to deal with such mechanism as the teacher is allowed to deal with the child. If the nervous system be the physical basis of education-and it is-then ample provision should be made for training every teacher, primary and secondary alike, in properly equipped laboratories, in a knowledge of the structure and functions of this allimportant mechanism. In a modern laboratory of hygiene the teacher will see something of scientific method whereby his serses will be quickened, his faculties of observation and reason developed, and the new thought brought to him that hereafter he may do less for his students than he did in the past when the communication of facts was his sole aim, but that what he does must be intensely purposeful. Working with a sympathetic and experienced man of science he will learn that hygiene is a summation of all the sciences which throw light on the growth, development, and vital activities of man; that it investigates the laws which govern the production and preservation of the highest forms of physical and mental health; that its object is to enlarge the horizon of man's happiness and to present him with all that is richest, highest, and noblest physically and psychologically in life; and that education is the key which opens the gate to this priceless inheritance. Herein he will be led to perceive the unity of education, hygiene, and life. Need it be inquired whether such experience will clothe his profession with a new dignity, open up new sources of interest, and drive him to acquire a larger and fuller equipment wherewith be shall better discharge the responsibilities of his high office? The true and effective way of training the teacher is to imbue him with broad and fruitful principles which he himself must bring to bear on the living problems which every day in school sets him to solve. Let him once behold this vision of scientific method and he will see that his own education no less than that of his pupils must last as long as life. He will return again and again to the laboratory to have his experience enlarged.

Combined with a sound training in principles in laboratories there should be ample provision made for the stady of childhood in action. Every training college should possess a department devoted to the practical study of child lite. Without a knowledge of the requirements of child life it is impossible for teachers to apply the principles of hygiene in schools. Such a training will demonstrate that hygiene must have a place in everything pertaining to infant life, school life, and the after life in the world; that hygiene is but an aspect of education in which the paramount concern is the completest possible adjustment of the individual with his physical and psychological environment; that it is not to be regarded so much as a new subject as the scientific application to everyday life of what we know concerning the factors engaged in the bighest physical and mental development, and the means of preventing abnormal development and disease. Hygiene directs effort to the bettering of man's estate, and in its relations with school life is not confined only to such subjects as food, air, clothing, heat, light, school furniture, ventilation, floor space, books, codes, and hours of work and play, but takes knowledge of the individual at all his points of contact with the world. It teaches, for example, that stupid docility is the necessary consequence of defective brain structure; that attention is necessary to brain growth and development as exercise is to muscular growth and development; that interest is the condition of attention, and that therefore when in a lecture room the limit of close attention is reached the lecture should close, since the educational process has stopped; that habit is the result of the repeated passage of stimuli along the same nerve tract; that nerve activity begets nerve activity; and that spontaneity and originality of thought are impossible apart from vigorous activity of many nerve centres vitally connected by paths of association. From such information the teacher will perceive that there is a great gulf fixed between education and instruction. Educational authorities and syllabuses are but the dry bones of education; it is the man behind the syllabus, aflame with that enthusiasm which can be kindled only at the laboratorv bench, and endowed with that sympathetic personality a: $d$ love of his subject which lights up a corresponding fire in the breast of his student, alone that counts This type of work is outside and beyond legislation, authorities, and codes. It can be done only by those who porsess a full and personal knowledge of the subject taught, not a secondhand information received from books or the dry-as-dust lecturer behind a rostrum, but living experience from experimental and practical work in the best laboratories.
As a method of mental training incidental and experimental teaching in hygiene will arouse curiosity, develop observation, and implant in the mind a love for natural science. As the principles of hygiene rest on chemistry and physics, the basal sciences of biology, and as many teachers to-day possess but scant knowledge, if any, of these sciences, more especially of the practical use of the test-tube, micro scope, and scalpel, much judgment is necessary in the selection of types of experimental work either in the form of demonstrations by the lecturer or practical work required of the teachers themselves, if the training is really to tell as a true educational instrument. Abundant practical material should be supplied in the courses and the students should do as nuch experimental work as their previous train. ing will permit.

In things of hygiene the more the teacher knows of natural science the better, provided he can bring his knowledge to bear upon the phenomena which surround him and which shape or obstruct his relations with other animate or inanimate beings; and further, provided he can utilise his scientific training in leading his students to observe for themselves facts and their relations to other facts, rather than in instructing them in what they should look for and see for themselves.

\section{A CASE OF VINCENT'S ANGINA IN WHICH THE LARYNX AND TRACHEA WERE INVOLVED.}

BY H. W. BRUCE, M.D. Lond., F.R.C S. ENG., MEDICAL SUPERINTENDENT, SOUTHWARK INFIRMARY.

IN The LaNCET of July 16th, 1904, p. 135, I related the histories of ten cases of Vincent's angina which had come under my notice before that date, two of them being severe forms and ending fatally. Since then $I$ have observed from time to time instances of the disease, all of them mild in type with the single exception recorded below. The striking naked-eye resemblance to diphtheria which is so characteristic of the disease has been well marked in the majority of these patients. In the case in which the disease was of more severe type the morbid process not only involved the fauces but attacked also the mucous membrane of the larynx and trachea. So widespread a lesion is uncommon and the case appears therefore worthy of record.

The patient was a man, ager 47 years, who was admitted to the Southwark Infirmary on Jan. 26th. He was suffering from a purpuric rash, mainly on the lower extremities, which had been present, he stated, for about five days. For the same period he had had diarrboea with some blood in the motions. There was a history of syphilis 12 years before. His temperature was $100 \cdot 4^{\circ} \mathrm{F}$. A mild degree of pyorrbca alveolaris was present. He made no complaint of his throat and the fauces were not examined. On the next day he was seized suddenly with obstruction to respiration. This rapidly increased until complete unconsciousness developed, with twitchings of the extremities, extreme cyanosis, and marked stridor. The obstruction was thought to be due either to the impaction of a foreign body in the larynx or to a sudden cedema of the glottis, and death being imminent laryngotomy was performed. From 10 to 15 minutes elapsed before consciousness was regained. A substquent examination of the fauces showed a sloughing of the uvula and of the edge of the soft palate typical of Vincent's angina. The characteristic bacilli were present in large numbers in smears taken from the slough but no spirilla were discovered. The laryngotomy tube had to be retained for five days, at the end of which time the patient could breathe comfortably through the larynx and could phonate, though his voice was hoarse. Meanwbile, there were a good deal of cough, with expectoration, and a very foul and profuse discharge from the laryngotomy tube. The tissues of the neck around the wound became somewhat swollen and indurated during the first two or three days and were then attacked by a sloughing process. The sk in and subcutaneous tissues, over an area which rapidly increased in size, were converted into a grey fotid material, the surface of which became quickly dry and black. This gangrenous process spread both outwards and downwards on both sides of the neck, extending on the left side as low as the clavicle. It then ceased to increase and a sharp line of demarcation began to form between the necrosed area and the neighbouring tissues. The latter were only slightly 
swollen and injected. The patient's general condition became steadily worse Signs of involvement of the lungs developed, with much cough and foul expectoration; the temperature was intermittent, and profuse diarrhoea set in towards the end. He died on Feb. 6th, 11 days after admission.

Neoropsy. - At the post-mortem examination the uvula was found to have sloughed and to be on the point of separating. The lateral edges of the epiglottis and the edges of the aryteno-epiglottidean folds were covered with a superficial green slough, the edges of the epiglottis being a little eroded where parts of the slough had separated. The mucous membrane of the larynx below the false cords and of the trachea

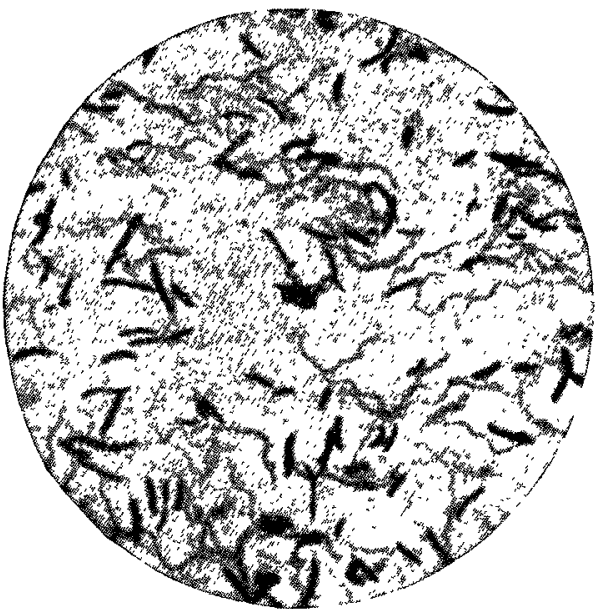

Micro-organisms in Vincent's angina.

almost down to the bifurcation was covered with the same thin green slough. Several of the rings of the trachea were, in fact, laid bare by the complete destruction of the mucous membrane over them, but with the exception of these limited areas the process was quite superficial. The gangrenous process which had developed in the tissues of the neck was found to have involved the skin and subcutaneous tissues only. There was a little purulent infiltration in its immediate neighbourbood. The lungs were very extensively involved in a diffuse broncho-pneumonia with a number of small abscesses.

Remarks - The extensive area attacked and the development of acute respiratory obstruction are both most unusual features. The involvement of the tissues of the neck in a gangrenous process is also of great interest. The lesion certainly seemed to resemble very closely that which is described as characteristic of the mild form of phagedæna or hospital gangrene. The relation between this disease and Vincent's angina was first pointed out by Vincent, who discovered similar micro-organisms in both, and it seems fair to presume that in the case recorded the process which developed in the neck was secondary to that in the respiratory tract, and resulted from direct infection of the laryngotomy wound by the discharges from the largnx and trachea.

Southwark Infirmary, S.E.

\section{"HYGIENE" AS A SCHOOL SUBJECT IN ELEMENTARY SCHOOLS.}

BY HENRY R. KENWOOD, M.B., C.M. EDIN., L.R.C.P. LOND , D.P.H.,

PROFESSOR OF HYGIENE AT UNIVERSITY COLLEGE, LONDON; MEDICAT OFFICER OF HEALTH OF THE: MFETROPOLITAN BOROUGH OF STOKE NEWINGTON, LONDON, N.

UPON the value of the precept and practice of hygiene in schools I need only make a passing reference, for it is now agreed upon all sides that the habits which make for the mairtenance of health determine in such great measure the happiness, usefulness, and general well-being of mankind that the formation of these habits is of paramount importance in education.

The object of this short paper is to suggest the best mean by which the hygienic habit of mind may be cultivated among scholars in elementary schools, and also to advance the proposition that there is little, if any, advantage in teaching hygiene as a set subject to such scholars, if one

1 A paper read at the Second International Congress of School Hygiene held in London, August, 1907. excepts some special instruction for girls in the last two standards.

School teachers, while recognising the high importance of the subject, ask for some scheme which will make as little demand as possible upon an already over-burdened school time-table, for there is insufficient time at present devoted to the recognised school subjects and the school hours are already quite long enough. The addition of yet another "subject" is therefore regarded with considerable concern; and one is faced with the further difficulty that the future teacher in the training college bas a crowded period of training which already makes a heavy demand upon his or her mental encrgies. But if nothing is dealt with but what is of real practical value to the scholar, if we do not make the mistake of calling simple things by elaborate names and of attempting to treat on a scientific basis facts which stand in no need of such treatment, and if this teaching and training is spread over the whole sohool ourrioulum, it should make bot little demand upon the time and energy of the teachers, either in acquiring the necessary knowledge or in communicating it to the scholars.

I am aware that some advocate the lightening of the burden of the present syllabus for elementary schools. Whether this can be done without prejudice to the scholars needs is a matter for the educational authority to decide upon; but I do not hold that any such concession is demanded by a practical scheme of hygienic teaching and training in elementary schools.

So it seems that only the barest essentials of the subject can be dealt with under our scheme of elementary education; and in deciding what knowledge must be imparted we must ask ourselves at every step, Is it essential that this should be known? Is it knowledge which can be applied-or is it necessary for the comprehension of an essential fact? Any scheme which aims at more than this will, in my opinion, fail to realise the best results.

Now the goal of hygienic teaching and training is to establish hygienic habits. To this end teaching is of little value, especially to those of 14 years of age and under, as compared with training; and if we could secure a skilled training in hygienic observances throughout the school age and in those cases where it appears to be necessary could supplement the school influences by an effort to improve the home conditions I believe that the results would lose little in comparison with those obtained if set teaching were added to the simple scheme which I advocate.

I am of opinion that for the purposes of elementary education there is no need to treat hygiene as a set subject; the practice and precept of hygiene should permeate the whole school carriculum. To treat it as a set subject upon which, say, two hours a week of teaching are to be bestowed will, in my opinion, be pretty sure to lead to poor results. The question then becomes, What is the scheme for obtain ing the best possible results under the conditions imposed by the already crowded syllabus and the early ages of the scholars? I am fully aware that the scheme I suggest as applicable to elementary education will be judged by many as insufficient. But although we may disagree on that point it will perhaps be generally conceded that it is desirable, at least in the first place, to start with a nseful instalment of essentials only, and if it is possible and desirable (as the result of experience) to extend the scheme later the further details could be gradually evolved in the working of the scheme itself. Train the children in cleanliness and self-respect, inculcate the fresh-air habit, and teach the elder girls something of the care of babies and of simple cooking, and there is little more that elementary education need provide in the cause of hygiene. Therefore the scheme which I would advocate for boys and girls alike would embrace the following items. 1. The importance of fresh air and how to obtain it. 2. The importance of cleanliness of person and surroundings. 3 The healthy maintenance of certain bodily functions and the formation of hygienic habits. 4. The dangers of contamination of water, air, and food, and how to guard against them in the home. 5. Temperance in all things. 6 (For girls.) The elementary facts of the care of infants and the selection of food (marketing, \&c.) and simple cooking (dealing only with the preparation of simple dishes by the simplest means).

Up to and including Standard III. I would advocate little more than the training by object-lessons, but in the higher standards the nature and value of the object-lessons should 